\section{Emergency Management of Chemical Burns}

\section{Medhat Emil Habib*, Mazen Al-Samarrae, Fathy El Said Shoeib and Gihan Adly Latif}

Department of Plastic \& Reconstructive Surgery, Mafraq Hospital, Abu Dhabi, United Arab of Emirates

\section{Introduction}

Chemical burns can be caused by acids, bases, organic and inorganic solutions. More than 25000 products which can cause chemical burns are available for use in agriculture, household, industry and military forces [1]. Chemical burn accounts for 2.4\%$10.7 \%$ of the overall percentage of burns with a mortality rate of $30 \%$ of all burn deaths $[2,3]$. The recognition of the causes, types and mechanisms of tissue destruction of the chemical agents can help in the management of this type of burns.

\section{Patient's History}

Knowing the cause of the burn is of paramount importance in the management. Sometimes this can be easily known if the patient or rescuers bring the name of the causative agent as in industrial burns in which a factory may be working on special types of chemicals or in domestic burns in which the material used may be known. On the other hand, the nature of the causative agent used may not be known as in criminal attacks and wars [4]. In some cases of domestic chemical burns a chemical material used for cleaning may be kept in a different container which can be attractive to children. There is another group of patients who know the chemical agent used but they do not declare it in the history as in suicidal actions and in some self inflicted cases which makes the task difficult for the clinician [5].

The increased use of chemical peeling in the last few years created a new category of chemical burn cases who can have serious complications [6]. Other causes of chemical burns can be due to extravasation of some drugs from the intravascular compartment to the surrounding tissues with the result of sustaining burns to these tissues [7].

Leakage of the hydrochloric acid around a PEG tube inserted in the stomach can cause burn in the surrounding skin (Figure 1).

*Corresponding author: Medhat Emil Habib, Department of Plastic \& Reconstructive Surgery, Mafraq Hospital, Abu Dhabi, United Arab of Emirates, Tel: 00971505368188; E-mail: medhatemil1@hotmail.com

Citation: Habib ME, Al-Samarrae M, Shoeib FE, Latif GA (2014) Emergency Management of Chemical Burns. J Emerg Med Trauma Surg Care 1: 001.

Received: June 11, 2014; Accepted: August 12, 2014; Published: August 26, 2014
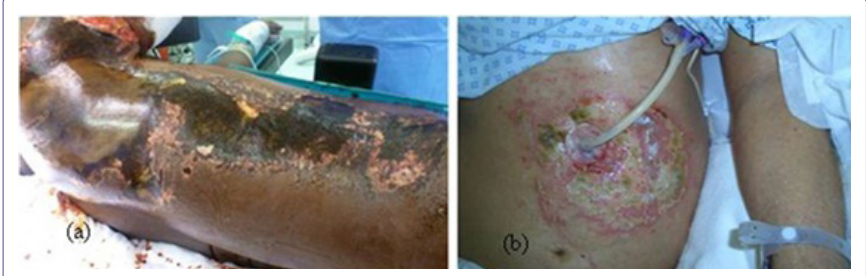

Figure 1: (a) Chemical burn right side of the trunk, (b) Stomach acid leakage around a PEG tube.

The history should also include the duration of contact with the chemical agent, change of voice or difficulty in breathing in cases of inhalation of a chemical agent, the medical condition of the patient and past history of previous experience with chemical burns as in industrial workers.

\section{Clinical Picture}

The patients may complain of itching, burning sensation, difficulty in breathing and coughing of blood as in inhalation of a chemical gas and difficulty in swallowing in cases of ingestion of chemical agent by children and in suicidal attempts [8]. The patient may have bleaching or darkening of the skin. The chemical burn can take the shape of patches of skin burns in cases of immersion of part of the body in contact with a chemical agent. Streak lines going along the gravity direction and patches of burn as a result of splash of a chemical liquid are characteristic presentations of chemical burns (Figure 2).

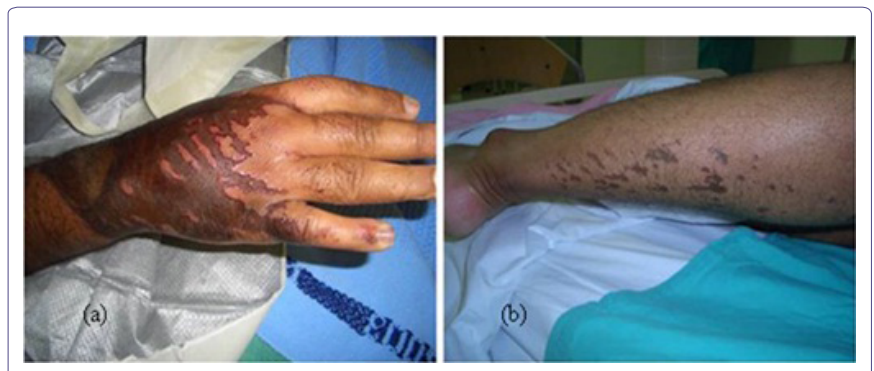

Figure 2: (a) Streak lines of flow of the chemical liquid, (b) Splash of the chemical on the leg.

The burnt area may be superficial or deep depending on the type of the chemical, its concentration, its duration of contact and its penetration into the skin. Most acids produce a coagulation necrosis by denaturing proteins, forming a coagulum (eschar) that limits the penetration of the acid. Bases typically produce a more severe injury known as liquefaction necrosis. This involves denaturing proteins as well as saponification of fats which does not limit tissue penetration [8]. Depression of the burn area compared to the surrounding skin on presentation to the emergency department is another characteristic sign of deep chemical burn (Figure 3).

\section{Management}

Hazardous chemical materials can be harmful to the patients and to the emergency medical staff who attend them. Training of the emergency staff and the use of personal protective equipment in dealing with such situations can reduce that risk [9]. The $\mathrm{ABC}$ of 


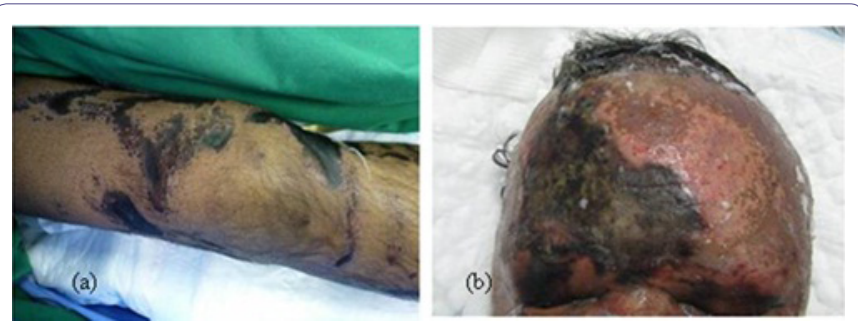

Figure 3: (a) Depression of burnt areas at the knee region, (b) Depressed chemical burn on forehead and eyelids.

trauma, primary and secondary assessment and all general principles of Trauma and Burn care apply to chemical burns [10]. The emergency doctor should be aware that chemical burn, in contrast to thermal burn, can continue in the emergency room especially if the clothes of the patient are soaked with the chemical material and kept on him. Another characteristic point of chemical burn is that it may act in a systemic fashion. Accordingly, the first aid management of the chemical burns should include several aspects as:

- Removal of the chemical agent.

- Treatment of the systemic toxicity if present and other side effects of the agent.

- General support of the patient.

- Consideration to specific areas of the body affected [10].

The chemical agent should be removed as early as possible. The involved clothes and foot wear should be removed. Irrigation of the chemical by water lavage should be started to dilute and even remove the chemical. Periods of 30 minutes of copious irrigation for acid burns and even longer periods for alkali burns may be required. Irrigation can be repeated if required. In case of burns from chemical powder irrigation should not be immediately started as the water can activate the chemical. The powder should be dusted off first and then the irrigation can take place. There is debate about the use of antidotes. Antidotes can produce an exothermic reaction that will superimpose a thermal injury on top of the chemical injury and they themselves can cause toxicity [11]. However, antidotes may be used in some special situations as in phenol burns which should be swabbed with polyethylene glycol sponges prior to a high-density shower. Muriatic and sulfuric acid burns should be neutralized with soap. Hydrofluoric acid dissociates into hydrogen and fluoride. The fluoride chelates the calcium in the body and the patient can develop hypocalcaemia. The patient is treated with a combination of water lavage, topical calcium gluconate gel and subcutaneous injection of $10 \%$ calcium gluconate to neutralize free fluoride ions. In some cases intra-arterial infusion of calcium gluconate may be required [11-13].

White phosphorous, used in the military, in fireworks and in some insecticides may ignite spontaneously on exposure to air. Recommended treatment includes lavage with $0.5 \%$ to $2 \%$ copper sulfate and copious water lavage. Copper sulfate also turns phosphorus particles black. This facilitates their identification and removal [10]. Toxicology consultation is preferred especially in cases of systemic toxicity which can be caused by some chemicals as hydrofluoric and foramic acids.

General support of the patient involves the use of conventional burn formulas for resuscitation when necessary, monitoring the vital signs and assessing the urine output. Blood gas and electrolyte analysis should be performed until metabolic stability has been assured. Hypothermia which may result from the copious irrigation has to be avoided by maintaining the room temperature between $28-31^{\circ} \mathrm{C}$ and the lavage water temperature as near to the body temperature as possible.

Clinical assessment of the depth and extent of a chemical burn is required. The blisters have to be debrided and covered with chemotherapeutic agents and dressings [10]. Local debriding agents as debridase and Laser may be helpful [14]. Early excision and grafting of non-viable tissue is advocated as soon as possible (Figure 4).
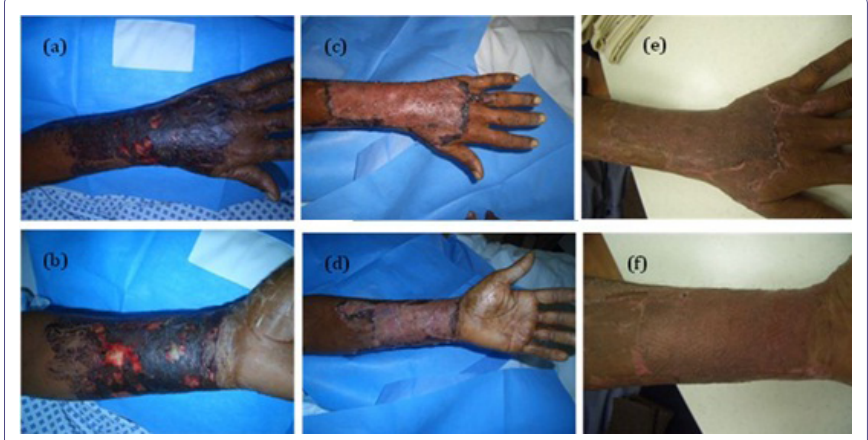

Figure 4: Acid burn, a) Dorsum of the left hand, b) Volar aspect of the left forearm, c) 10 dyas after application of unmeshed skin graft of the dorsum of the left hand, d) Meshed graft of the volar aspect of the left forearm, e) 4 months later and f) 4 months later.

\section{Inhalation Injury}

Concomitant respiratory injuries may occur when aerosolized chemical or smoke is inhaled. The practitioner must be aware of the possibility of inhalation injury in all cases of chemical burns. The diagnosis is usually made with the fiber optic bronchoscope. Chemical inhalation injuries, like smoke inhalation injuries, are managed with airway protection and supplemental oxygen, by mechanical ventilation with positive end-expiratory pressure and aggressive chest physiotherapy [12].

\section{Chemical Burns of the Eye}

Chemical eye burns account for small but significant percentage of ocular trauma. The incidence of chemical and thermal injuries to the eye ranges from $7.7 \%-18 \%$ of all ocular trauma $[15,16]$. Alkali injuries occur more frequently than acid injuries. Irreversible damage occurs at a $\mathrm{pH}$ above 11.5 [16]. Acid causes less severe and more focal tissue injury [17]. The Hydrogen ion alters surface $\mathrm{pH}$ while the associated anion reacts with epithelial and superficial stromal cells to precipitate and denature surface proteins. Eye burns are classified into 4 grades; I and II are associated with hyperemia, small conjunctival ecchymosis and chemosis as well as erosion of the corneal epithelium. In mild acid burns, the coagulated corneal epithelium often has a "ground-glass" appearance. After removal of epithelium the clear corneal stroma is visible. Grade III and IV are accompanied by extensive and deep damage to the tissue. The visible blood vessels are thrombosed and appear dark. The corneal keratocytes are lost and hydration of the denatured proteins results in corneal opacification. Chemical injury to the iris and crystalline lens may produce mydriasis. The lysis of cells of the anterior chamber destroys the blood aqueous barrier and leads to iridocyclitis and fibrinous exudation [16].

The goal of the therapy is to restore a normal ocular surface and corneal clarity. Patients with a chemical injury will often present with sudden onset of severe pain, epiphora and blepharospasm after 
exposure to the inciting pain. Chemical agent should be identified but this should not delay the onset of the treatment. Immediate treatment should include copious irrigation prior to ophthalmic evaluation and $\mathrm{pH}$ testing [18]. Litmus paper is an easy way of determining the $\mathrm{pH}$ of the conjunctiva [19]. Early involvement of toxicologist or Poison Control Center is essential in such cases.

In initial ocular examination, there should be an examination of the fornices to ensure that there is no remaining alkaline material such as ammonia or lime. This can be done by sweeping the fornices with a glass rod. Irrigation with isotonic saline or lactated Ringer's solution should be performed to change the $\mathrm{pH}$ to a physiologic level. Then ocular examination will proceed to visual acuity, intraocular pressure and perilimbal blanching/ischemia. If the injury is minor, preservative free artificial tears is used to promote reepithelization. A bandage contact lens may provide the patient with more comfort. Fourth generation topical antibiotic such as Fluoroquinolone can be used in large epithelial defect as prophylaxis. Aqueous suppression may be also used in elevated intraocular pressure. Close follow up is required. In severe cases in addition to conservative therapy, active surgical intervention may be required [18].

\section{Conclusion}

Although chemical burns constitute a small percentage of the overall burn affecting the human body, their morbidity and mortality rates are high. Proper history taking, clinical examination and early management of such cases can greatly reduce the morbidity and mortality rates of these patients.

\section{References}

1. Van Hasselt EJ (2008) Chemical burns. In: Burns Manual. (2ndedn), Nederlandse Brandwonden Stichting, The Netherlands. Pg no: 79-80.

2. Vaglenova E (1997) Chemical Burns- Epidemiology. Annals of Burns and Fire Disasters 10: 1 .

3. Hardwicke J, Hunter T, Staruch R, Moiemen N (2012) Chemical burns - An historical comparison and review of the literature. Burns 38: 383-387.

4. Kales SN, Christiani DC (2004) Acute Chemical Emergencies. N Engl J Med 350: 800-808.

5. Dilsiz A (2010) Self-Inflicted Oral Soft-Tissue Burn Due to Local Behavior and Treatment. J Clin Exp Dent 2: 51-54.
6. Nikalji N, Godse K, Sakhiya J, Patil S, Nadkarni N, et al. (2012) Complications of medium depth and deep chemical peels. J Cutan Asthet Surg 5: 254-260.

7. Sharma R, Yoshikawa H, Abisaab J (2012) Chemical Burn Secondary to Propofol Extravasation. West J Emerg Med 13: 121-122.

8. Touzopoulos $\mathrm{P}$, Zarogoulidis $\mathrm{P}$, Mitrakas $\mathrm{A}$, Karanikas $\mathrm{M}$, Milothridis $\mathrm{P}$, et al (2011) Occupational chemical burns: a 2-year experience in the emergency department. J Multidiscip Healthc 4: 349-352.

9. Kirk MA, Cisek J, Rose RS (1994) Emergency Department Response to Hazardous Materials Incidents. Emergency Medicine Clinics of North America 12: 461-469.

10. Palao R, Monge I, Ruiz M, Barret JP (2009) Chemical burns: Pathophysiology and treatment. Burns 36: 295-304.

11. Klein MB (2007) Thermal, Chemical and Electrical Injuries. In: Charles H Thorne (eds.). Grabb \& Smith's Plastic Surgery, (6thedn). Lippincott Williams \& Wilkins, Philadelphia, USA. Pg no: 132-149.

12. Cartotto RC, Peters WJ, Neligan PC, Douglas LG, Beeston J (1996) Chemical Burns. Can J Surg 39: 205-211.

13. Vance MV, Curry SC, Kunkel DB, Ryan PJ, Ruggeri SB (1986) Digital hydrofluoric acid burns: Treatment with intraarterial calcium infusion. Ann Emerg Med 15: 890-896.

14. Eldad A, Weinberg A, Breitermanb S, Chaouatb M, Palankerc D, et al. (1998) Early nonsurgical removal of chemically injured tissue enhances wound healing in partial thickness burns. Burns 24: 166-172.

15. Morgan SJ (1987) Chemical burns of the eye: causes and management. $\mathrm{Br}$ $\mathrm{J}$ ophthalmol 71: 854-857.

16. Kuckelkorn r, Shrang N, Keller G, Redbrake C (2002) Emergency treatment of chemical and thermal eye burns. Acta Ophthalmol scand 80: 4-10.

17. Spector J, Fernandez W (2008) Chemical,Thermal, and biological ocular exposure. Emerg Med Clin North Am 26: 125-136.

18. Fish R, Davidson RS (2010) Management of ocular thermal and chemical injuries, including amniotic membrane therapy. Curr Opin Ophthalmol 21: 317-321.

19. Zentani A, Burslem J (2009) Use of Litmus Paper in Chemical Eye Injury. Emerg Med J 26: 887. 